\title{
Tematizando as lutas na educação física escolar: relato de uma prática pedagógica no contexto do PIBID
}

\author{
Fights as themes in physical education classes: report of a pedagogical \\ approach in the context of PIBID
}

DOI: http://dx.doi.org/10.36453/2318-5104.2018.v16.n1.p109

\author{
Marlon Messias Santana $\mathrm{Cruz}^{1}$, Abília Ana Castro Neta ${ }^{2}$, Drieli Fernandes Boa Sorte ${ }^{1}$, \\ Joice Tainá de Jesus Santos ${ }^{1}$, Ana Gabriela Alves Medeiro ${ }^{1}$ \\ ${ }^{1}$ Universidade do Estado da Bahia (UNEB) \\ ${ }^{2}$ Universidade Estadual do Sudoeste Baiano (UESB)
}

\begin{abstract}
RESUMO
Este estudo foi desenvolvido no âmbito do Programa Institucional de Bolsa de Iniciação à Docência no contexto do subprojeto "Educação Física escolar: construindo possibilidades pedagógicas a partir de uma perspectiva cultural" do curso de licenciatura em Educação Física da Universidade do Estado da Bahia (UNEB) - Campus XII. As ações pedagógicas foram desenvolvidas em uma instituição de ensino básico da rede pública, situada no município de Guanambi (BA), compreendido no período de março a novembro de 2017. As informações necessárias à elucidação do problema da pesquisa foram produzidas no contexto da intervenção pedagógica e posteriormente sistematizadas e analisadas. Essas informações foram coletadas por meio de registros reflexivos - ou diários de bordo - realizados cotidianamente, nos quais foram transcritos detalhes relativos ao desenvolvimento das aulas. Foi utilizado também, como fonte para a obtenção dos resultados, a gravação em áudio das discussões e rodas de conversa. A partir dos desdobramentos decorrentes das problematizações e da avaliação realizada ao final do ano letivo, identificamos nos alunos uma possível desconstrução das representações ou signos da cultura dominante, inicialmente presentes em seus discursos. Ao final, identificamos, a partir das problematizações e vivências, que alguns discursos estereotipados a respeito das lutas se desestabilizaram.
\end{abstract}

PALAVRAS-CHAVE: Currículo; Educação Física Escolar; PIBID.

\section{ABSTRACT}

This study was developed within the scope of the Institutional Scholarship Initiative Program in the context of the subproject "Physical School Education: building pedagogical possibilities from a cultural perspective" of the undergraduate course in Physical Education of the University of the State of Bahia (UNEB) - Campus XII. The pedagogical actions were carried out in a public elementary school located in the municipality of Guanambi-Ba, from March to November 2017. The information needed to elucidate the research problem was produced in the context of pedagogical intervention and Later systematized and analyzed. This information was collected through reflective records - or daily logs - carried out daily, in which details related to the development of the classes were transcribed. It was also used, as a source for obtaining the results, the audio recording of discussions and talk wheels. From the developments resulting from the problematizations and the evaluation carried out at the end of the school year, we identified in the students a possible deconstruction of the representations or signs of the dominant culture, initially present in their discourses. In the end, we identified, from the problematizations and experiences, that some stereotyped discourses about the struggles were destabilized.

KEYWORDS: Curriculum; Physical Education; PIBID. 


\section{INTRODUÇÃO}

Nos cursos de licenciatura, a aproximação da universidade com a realidade escolar é uma necessidade formativa, mas esse contato muitas vezes fica restrito ao momento do estágio curricular supervisionado. Nesse contexto, nota-se o surgimento de iniciativas políticas que visam fortalecer essa aproximação, e uma delas é o Programa Institucional de Bolsa de Iniciação à Docência (PIBID).

O PIBID é um programa da Coordenação de Aperfeiçoamento de Pessoal de Nível Superior (CAPES) que tem por finalidade fomentar a iniciação à docência, contribuindo para o aperfeiçoamento da formação de docentes em nível superior e para a melhoria da qualidade da educação básica pública brasileira.

Este estudo foi desenvolvido no âmbito do PIBID no contexto do subprojeto "Educação Física escolar: construindo possibilidades pedagógicas a partir de uma perspectiva cultural" do curso de licenciatura em Educação Física da Universidade do Estado da Bahia (UNEB) - Campus XII , cujo propósito consiste em contribuir para a construção da legitimidade da Educação Física na escola, a partir da efetivação de uma prática pedagógica orientada por princípios democráticos e de valorização da diversidade, que possibilite uma leitura crítica da realidade social.

As ações pedagógicas do subprojeto sustentam-se no currículo cultural da Educação Física, proposto por Neira e Nunes $(2008 ; 2009)$ a partir do referencial teórico dos Estudos Culturais e do Multiculturalismo Crítico. O currículo cultural da Educação Física tem como objetivo a formação de um sujeito ativo-crítico socialmente, que seja suficientemente capaz de se posicionar e lutar por condições de vida e por relações sociais mais democráticas.

A partir desta perspectiva, buscamos neste trabalho apresentar e refletir acerca do trato pedagógico do conteúdo "lutas" nas aulas Educação Física no campo do PIBID - UNEB - Campus XII. Consideramos que o trato pedagógico com as lutas é uma tarefa que se apresenta primordial, pois tal prática vem sendo negligenciada no contexto escolar, em decorrência de argumentos como falta de competência técnica sobre tal conteúdo, infraestrutura ausente ou inadequada, vinculação das lutas com violência e agressividade e até mesmo a resistência dos próprios alunos (FERREIRA, 2006).

Nesse sentido, o trabalho com lutas, quando realizado, se restringe a uma análise conceitual de tal conteúdo. Transformar tal situação, além de possível, é essencial, pois negar tais vivências aos estudantes é limitar-Ihes o direito ao repertório cultural existente na sociedade. Constitui uma barreira para compreenderem, analisarem e questionarem as inúmeras manifestações relacionadas a temática que se impõe no cotidiano. Para tanto, o trato pedagógico com as lutas, demanda muito mais competência cognitiva do que técnica. Mobilizar tais competências é essencial para a prática pedagógica, ao passo que o professor deve tematizar as práticas corporais dos vários grupos que coabitam a sociedade, engajado na luta por mudanças sociais, priorizando procedimentos democráticos para a definição dos temas e atividades de ensino, além de valorizar experiências de reflexão crítica sobre a ocorrência social das práticas corporais, aprofundando e ampliando os conhecimentos dos alunos mediante o confronto com outras representações.

\section{MÉTODOS}

Este estudo se consiste em um relato de experiência que, segundo Cavalcante e Lima (2012, p. 96), "é uma ferramenta de pesquisa descritiva que apresenta uma reflexão sobre uma ação ou um conjunto de ações que abordam uma situação vivenciada no âmbito profissional de interesse da comunidade científica".

Os procedimentos de intervenção pedagógica foram norteados pelos princípios do currículo cultural da Educação Física. Primeiramente, no processo denominado de mapeamento, levantamos os conhecimentos que os alunos possuem sobre determinada prática corporal. Portanto, durante o mapeamento, não há padrão ou roteiro obrigatório a ser seguido.

O segundo processo é a tematização, que implica em abordar, interpretar, reconstruir, conferindo-lhes novos significados sobre o tema selecionado. Assim, são convidados, por meio de problematizações e debates, a produzirem novas formas de vivenciar a prática em questão, em conformidade com as formas de regulação 
que ocorrem no âmbito das aulas, e a relacionarem esse processo com as formas como a prática corporal investigada se manifesta na sociedade mais ampla. Esse procedimento é denominado de ressignificação.

As ações de aprofundamento e ampliação dos saberes referentes à prática corporal tematizada, por sua vez, permitem aos alunos conhecer aspectos culturais referentes à política, à história, aos saberes populares e científicos, entre tantos outros que o trabalho possa requerer.

Por fim, outra possibilidade de ação pedagógica que o currículo cultural da Educação Física nos direciona são os registros e avaliação. A avaliação no currículo cultural se caracteriza pela adoção de uma postura etnográfica, para além das observações, os professores registram as ações didáticas desenvolvidas, os encaminhamentos efetuados e as respostas dos educandos. Também recolhem e arquivam exemplares dos materiais produzidos pelos alunos durante as aulas.

A sistematização e análise dos resultados desta experiência foram feitas por meio de registros reflexivos - ou diários de bordo - realizados cotidianamente, nos quais foram transcritos detalhes e impressões relativas ao desenvolvimento das aulas e aos seus acontecimentos. Nesta perspectiva, Soldati (2005) afirma que através desta técnica é possível apresentar os problemas que surgiram durante o estudo, descrevendo as atividades desenvolvidas, comentários, reflexões e medidas utilizadas para superar os desafios e obstáculos encontrados.

Utilizamos também, como fonte para a obtenção dos resultados, a gravação em áudio das discussões e rodas de conversa. Para isso, foi feito o uso de um gravador na realização das intervenções pedagógicas, para que fosse ampliado o poder de registro das falas dos alunos e a captação de elementos de comunicação que pudessem ser significativos, tais como pausas de reflexão, dúvidas ou entonação da voz, aprimorando a compreensão da narrativa. Autores como Patton (1990) e Rojas (1999) corroboram com este indicativo, pois o gravador preserva o conteúdo original e aumenta a acurácia dos dados coletados.

As aulas que resultaram na elaboração deste relato ocorreram no período compreendido entre março a novembro de 2016. A temática estudada nesse período letivo foram os esportes olímpicos, em função dos Jogos Olímpicos decorrentes no momento. O cenário do estudo foi uma instituição de ensino básico da rede pública situada no município de Guanambi (Bahia), com uma turma do $2^{\circ}$ ano do ensino fundamental I.

\section{A PRÁXIS PEDAGÓGICA}

A prática pedagógica se configurou a partir de diferentes momentos interdependentes entre si. Organizadas pela temática geral dos Jogos Olímpicos, iniciamos o desenvolvimento da prática pedagógica com a temática Esportes Olímpicos, problematizamos junto ao tema megaeventos esportivos e seus legados para a sociedade, e as análises sobre os aspectos sócio/históricos do país.

No decorrer do processo de tematização do conteúdo esportes olímpicos, realizamos discussões, problematizações, vivências e experimentações práticas, cuja finalidade foi despertar novas informações acerca desse fenômeno que permeia a cultura corporal, trocar experiências e expandir os conhecimentos iniciais. Tematizar, na visão de Freire (1980) apud Neira (2010), implica procurar o maior compromisso possível do objeto de estudo numa realidade de fato, social, cultural e política. O que se pretendeu com a tematização foi uma compreensão profunda da prática corporal em foco e o desenvolvimento da capacidade crítica dos alunos enquanto sujeitos de conhecimento, desafiados pelo objeto a ser conhecido.

Nossos recursos visuais como slides, vídeos e fotos, nos deram maiores possibilidades de identificarmos discursos a respeito da luta como prática corporal. Dessa forma, estimulamos as crianças a relatarem seus saberes, refletirem sobre os mesmos, na intenção de possibilitarmos uma reflexão crítica.

Conforme Nascimento (2005), quando o fenômeno lutas aparece na escola, isso acontece pelas aberturas preconizadas por essa instituição para terceiros realizarem, em seu espaço, oficinas, voluntárias ou não, desvinculadas do componente curricular Educação Física e do projeto político pedagógico da escola.

No espaço de intervenção escolar, podemos afirmar que o tema/conteúdo de lutas é pouco acessado e, inclusive, o seu trato pedagógico suscita questionamentos e preocupações diversas por parte dos profissionais atuantes na Educação Física (NASCIMENTO; ALMEIDA, 2007, p. 92). 
$\mathrm{Na}$ tentativa de rompermos estes paradigmas, nas semanas posteriores tematizamos este conteúdo, especificamente as lutas presentes nos Jogos Olímpicos, a saber: boxe, esgrima, judô, luta olímpica e taekwondo. Para este relato, nos deteremos somente nas aulas com o conteúdo judô.

Ao tematizarmos o judô, discutimos acerca das suas origens, seus praticantes, quais grupos sociais pertencem, em quais espaços se realizam, quais os procedimentos envolvidos. Foram feitas diversas problematizações acerca das representações sociais inerentes a essa prática. Identificamos nos discursos dos alunos que as lutas, de modo geral, eram eminentemente violentas. Marginalizavam esta prática corporal e a associavam como sinônimo de agressão e/ou briga.

\section{“Luta é briga, tia!" (ALUNO A)}

Fato que nos levou a problematizar tais representações a fim de refletirmos sobre a marginalização desta prática corporal na Educação Física escolar e no contexto social mais amplo. As vivências foram realizadas por meio de brincadeiras com movimentos inerentes à luta. Segundo Neira (2011, p. 123), "no que tange às vivências corporais multiculturalmente orientadas, sua característica distintiva com relação às demais propostas do componente é a prática acompanhada de leitura e interpretação".

Para ampliar e aprofundar os conhecimentos a respeito da prática corporal em foco foram planejados momentos para assistir documentários e filmes, pesquisas na internet, em livros ou revistas, entrevistas com participantes, visitas a locais de prática, entre outras. Atividades como essas prescindem de uma busca pessoal do professor para que oriente os alunos acerca dos materiais, formato, procedimentos, pessoas envolvidas, etc. É o momento da recontextualização pedagógica (BERNSTEIN, 1996), ocasião em que o docente trabalha com textos culturais que contêm informações distintas, divergentes das acessadas pelos estudantes, o que faz gerar um ambiente contra hegemônico.

Corroborando com estes apontamentos, apresentamos aos alunos alguns discursos de lutadores profissionais - por meio de imagens, vídeos, etc. - que desconstruíam uma imagem eminentemente violenta das lutas. Além disso, agendamos uma visita a um local onde são desenvolvidas lutas distintas com a finalidade de ampliarmos o conhecimento acerca das mesmas. Para isso, propusemos que entrevistássemos professores e praticantes da academia de lutas visitada.

As atividades de ensino voltadas para o aprofundamento possibilitam um entendimento maior dos significados comumente atribuídos à prática corporal objeto de estudo. As atividades de ensino voltadas para a ampliação procuram confrontar os conhecimentos culturais inicialmente disponíveis com outros, estimulam o contato com discursos diferentes e enriquecem as leituras e interpretações realizadas.

Ao término do conteúdo lutas realizamos uma avaliação, onde foi analisado todo o processo de ensino/ aprendizagem. Indagamos acerca da diferença existente entre luta e briga.

"Na luta uma pessoa respeita a outra, cumprimenta. Na briga não..."

"A briga machuca!"

"Na luta tem respeito, na briga não tem!"

(Transcrições na íntegra da fala de alunos)

Questionamos também sobre o que eles aprenderam com o judô.

"Todas as pessoas podem participar: as crianças, os adolescentes, os adultos, as mulheres e os idosos."

"Tem que derrubar, tia!"

"O judô não deixa a gente brigar!"

(Transcrições na íntegra da fala de alunos) 
Entrecruzando as falas dos alunos no início das nossas problematizações com os discursos ao término das mesmas, identificamos uma possível desconstrução da imagem deturpada - eminentemente violenta e marginalizada - que estes possuíam acerca das lutas. Na prática pedagógica aqui relatada, a problematização esteve presente na tentativa de confrontar as representações que os alunos tinham a respeito da violência no âmbito das lutas. Ao final, conseguimos proporcionar uma reflexão sobre a marginalização desta prática corporal e de seus praticantes no contexto social mais amplo. A partir das problematizações e vivências, alguns discursos estereotipados a respeito das lutas se desestabilizaram. Neste sentido, relata Neira (2011, p. 116):

[...] quando problematiza os temas da cultura corporal, o currículo se transforma em um espaço de crítica cultural, no qual se propicia o questionamento sobre tudo que possa ser "natural e inevitável". A ideia é colocar em xeque e permitir novos olhares sobre aquilo com que usualmente lidamos de modo acrítico.

Assim, o Currículo Cultural da Educação Física vem desestabilizar o currículo dominante, colocar sua própria identidade em questão, pois a partir do momento que o papel do mesmo é expor a cultura marginalizada dos grupos subjugados da sociedade, aceitar as culturas vivenciadas pelos alunos e potencializar as vozes, ele vem dizer que o ambiente escolar deve reconhecer e oferecer espaço para um debate do processo da constituição das identidades dos alunos.

\section{CONSIDERAÇÕES FINAIS}

Um dos apontamentos dos Estudos Culturais para a pedagogia consiste no direcionamento dos olhares para as relações de poder. Neste sentido, ao dar a devida atenção a essas relações, torna-se necessário analisar sua origem, por meio de indagações que entrevejam a mudança já que a submissão dos diferentes não corrobora com os princípios democráticos propostos na atualidade para as escolas.

Nossas ações eram constantemente planejadas, refletidas, analisadas, num processo contínuo, sujeito a adaptações conforme as necessidades dos sujeitos envolvidos, aproximando e confrontando os conhecimentos dos alunos, promovendo o reconhecimento das diferenças, ao potencializar os interesses e as características socioculturais dos discentes.

Ao tematizarmos o conteúdo lutas, emergiram questões que nos possibilitaram problematizar representações e relações muitas vezes carregadas de opressão, submissão, estereótipo e preconceito, que adentram os espaços da escola e as vivências "naturalizadas" das manifestações da cultura corporal que se concretizam nesse contexto. A partir dos desdobramentos decorrentes das problematizações e da avaliação realizada ao final do ano letivo, identificamos nos alunos uma possível desconstrução das representações ou signos da cultura dominante, inicialmente presentes em seus discursos.

Foi possível apreender que o processo de desnaturalização apresentado nesse relato de experiência, resultantes das ações pedagógicas desenvolvidas (tematização, ressignificação, aprofundamento, ampliação, registros e avaliação), não é um fator comum que se concretize nas aulas de Educação Física Escolar, pois suscita o rompimento de paradigmas existentes, construídos social, cultural e historicamente na área.

A partir dos desdobramentos da prática pedagógica aqui relatada é possível verificar que nos colocamos como professores-pesquisadores. No decorrer do projeto, o professor-pesquisador continua mapeando os saberes e conhecimentos dos alunos, e de forma contínua, com idas e vindas, vai compondo o currículo, prioritariamente a partir das questões dos alunos em relação ao tema. Também como professor-etnógrafo, pois vai a campo, observa, estuda, se envolve, pesquisa em diversas fontes. Os alunos também assumem o papel de pesquisadores e etnógrafos, a medida em que vão coletando informações, assistindo aos vídeos, aprendendo conceitos, táticas, técnicas, conhecendo locais de prática, aprofundando, ampliando, registrando e ressignificando. 
Por tudo isso, corroboramos com os apontamentos de Neira (2011) ao defender uma noção curricular aberta ao diálogo cultural, na busca contínua por uma Educação Física da diferença, que desestabiliza o acomodado e desconstrói as certezas, por meio de um currículo que não se configura como uma proposta definitiva, mas como um caminho a seguir, pois outros são possíveis e necessários para uma prática pedagógica não estática.

\section{REFERÊNCIAS}

BARBOSA, C. H. G. B.; NUNES, M. L. F. A prática Pedagógica de um currículo cultural da Educação Física. Revista de Estudo e Pesquisa em Educação, Juiz de Fora, v. 16, n. 1, p. 59-69, 2014.

BERNSTEIN, B. A estruturação do discurso pedagógico. Classe, códigos e controle. Petrópolis: Vozes, 1996.

CAVALCANTE B. L. L.; LIMA U. T. S. Relato de experiência de uma estudante de Enfermagem em um consultório especializado em tratamento de feridas. Journal of Nursing Health, Pelotas, v. 1, n. 2, p. 94-103, 2012.

HALL, S. A centralidade da cultura: notas sobre as revoluções de nosso tempo. Educação e Realidade, Porto Alegre, v. 22, n. 2, p. 15-46, 1997.

NASCIMENTO, P. R. B. A capoeira no contexto da escola e da Educação Física. 2005. 145f. Dissertação (Mestrado em Educação das Ciências) - Faculdade de Pedagogia, Universidade Regional do Noroeste do Estado do Rio Grande do Sul, ljuí, 2005.

NASCIMENTO, P. R. B.; ALMEIDA, L. A tematização das lutas na educação física escolar: restrições e possibilidades. Movimento, Porto Alegre, v. 13, n. 3, p. 91-110, 2007.

NEIRA, M. G. Análises das representações dos professores sobre o currículo cultural da Educação Física. Interface - Comunicação, Saúde, Educação, Botucatu, v. 14, n. 35, p. 783-95, 2010.

NEIRA, M. G. Educação física. São Paulo: Blucher, 2011.

NEIRA, M. G. O currículo cultural da educação física: uma resposta aos dilemas da contemporaneidade. Revista Linhas, Florianópolis, v. 16, n. 31, p. 276-304, 2015.

NEIRA, M. G. O currículo da educação física frente à diversidade cultural: um estudo de caso. In: 31a Reunião Anual da Associação Nacional de Pós-graduação em Educação, 2008, Caxambu. Anais... Rio de Janeiro: Anped, 2008. v. 1 CD. p. 1-18.

NEIRA, M. G. Práticas corporais: brincadeiras, danças, lutas, esportes e ginásticas. São Paulo: Melhoramentos, 2014.

NEIRA, M. G.; NUNES, M. L. F. Contribuições dos estudos culturais para o currículo da educação física. Revista Brasileira Ciências do Esporte, Florianópolis, v. 33, n. 3, p. 671-85, 2011.

NEIRA, M. G.; NUNES, M. L. F. Educação física, currículo e cultura. São Paulo: Phorte, 2009.

NEIRA. M. G.; NUNES. M. L. F. Pedagogia da cultura corporal: crítica e alternativas. 2. ed. São Paulo: Phorte, 2008.

OLIVEIRA, G. N. B.; CRUZ, M. M. S. Educação física escolar: construindo possibilidades pedagógicas a partir de uma perspectiva cultural. In: SILVA, A. L. G.; FIGUEIREDO, C. S.; SALES, M. A. (Org.). Da iniciação à docência: ressignificando a prática docente. Salvador: Eduneb, 2016. p. 293-300.

PATTON, M. Q. Qualitative evaluation and research methods. London: SAGE; 1990.

ROJAS, J. E. A. O indivisível e o divisível na história oral. In: MARTINELLI, M. L. Pesquisa qualitativa: um instigante desafio. São Paulo: Veras, 1999. p. 87-94.

SILVA, T. T. Currículo e identidade social: territórios contestados. In: SILVA, T. T. (Org.). Alienígenas na sala de aula: uma introdução aos estudos culturais em educação. Petrópolis: Vozes, 2009. p. 190207.

SILVA, T. T. Documentos de identidade: uma introdução às teorias de currículo. 2. ed. Belo Horizonte: 
Autêntica, 2003.

SOLDATI, M. Capoeira: prevention et mediation educative au près de jeunesen situation de risque au Brésil. Genève: Univirsité de Genève. Mémoire de licence, 2005.

Autor correspondente: Marlon Messias Santana Cruz

E-mail: marlonmessias@hotmail.com

Recebido: 02 de fevereiro de 2018.

Aceito: $\mathbf{2 1}$ de março de 2018. 